\title{
Assessing the Respect and Dignity for Human Life in the Nigerian Health Sector
}

\author{
Marcus Garvey Orjii ${ }^{1}$, Felicia Onyenemerem ${ }^{2}$ \\ ${ }^{1}$ Department of Business Administration, Veritas University, Abuja, Nigeria \\ ${ }^{2}$ Department of Guidance and Counseling, Veritas University, Abuja, Nigeria \\ marcusorji@gmail.com
}

\begin{abstract}
Human dignity is 'an individual or group's sense of selfrespect and self-worth, physical and psychological integrity and empowerment. The basis for the theme of Human dignity, is that humans were created in the image and likeness of God. Regardless of any factors or reasons we can think of, individuals have an inherent and immeasurable worth and dignity; each human life is considered sacred and must be respected. Thus, the health sector has the obligation of considering the ethical dimensions of the major determinants of human health, respect and dignity. The objective of this study is to examine the issues of respect and dignity for human life in the Nigerian health sector. The study is a survey research, and data was collected from both primary and secondary source, and analysed by simple percentages and tabulations. The result of the findings revealed that respect and dignity for human life in the Nigerian health sector is very necessary; promotion and protection of human rights and of health care are fundamentally linked; Nigerian health workers have not fared well in the area of respect for human dignity, and that Nigerian government policies and cultures have impeded the protection of rights and dignity of persons in the health sector. The study among others recommended the education and change of mentality through media of the Nigerian health workers on the need for respect and dignity of human life in the health care institutions, reformation of the health care sector, planning it in such a way that respect and dignity for human life will reflect in the centrality of the programme of reformation and activities.
\end{abstract}

Keywords

respect; dignity, human life; Ngerianhealth sector

\section{Introduction}

Human life, God's precious gift, is most vulnerable when it comes into the world and when it leaves the realm of time to embrace upon eternity, when it comes into the world; it comes from the hand of God himself. Human life in its bodily nature is precious in itself and to God, at every moment of its existence, even and especially when it is weak, when it suffers, when it draws near to death. God's command "thou shall not kill (Ex 20:1 3; Dt 5: 17 ) is a specific command intended to protect the dignity and sanctity of human life; indeed. 
Konfrontasi Journal: Culture, Economy and Social Changes, 7 (1) March 2020, 20-28

ISSN: 1410-881X (Print), 2716-2095 (Online)

Marcus Garvey Orji, Felicia Onyenemerem: Assessing the Respect and Dignity for Human Life in the Nigerian Health Sector

https://doi.org/10.33258/konfrontasi2.v7i1.93

http://www.konfrontasi.net/index.php/konfrontasi2

The whole of God's law, his wise and loving plan for existence, fully protects human life. This law finds its fulfillment in Jesus who shows us the authentic meaning of human life, namely," that of being a gift which fully realized in the giving of self "in the gift of self in love for one's brothers and sisters or in the service of the suffering humanity.

The weakest period of human life is during the period of illness or sickness. This period in time nothing really matters everything becomes vanity of vanities, nothing has sense and human life is in question. In this condition human life is helpless and totally in need of help, medical attentions, care, empathy, sense of belonging, encouragement, need to be valued and given dignity. In this circumstance whether someone is rich or poor, tall or shut, beautiful or ugly, learned or illiterate, royal or outcast, a president or a hawker does not matter what is needed is equal respect and dignity for human life contrary to what is observed and experienced today in the health sector of our country Nigeria. There are two categories of individuals who come to seek medical attention in the health care sector. Those who come with illness or sickness serious or not serious and those who are not sick like pregnant women who come for medical advice / routine test and children for vaccination.

Both categories need special attention by means of verbal and non-verbal communication, personal interaction in order to reduce stress of waiting for a long time. Most of the time these pregnant women complain of the negligence attitude by the health workers, use of abusive languages and gross irresponsibility in the health care sector, and this is lack of respect for the dignity of human life. It is in the light of this that this study intends to assess the respect and dignity of human life in the Nigerian health sector.

\section{Statement of the Problems}

Although, there are lots of changes, initiatives, inventions, new and sophisticated technology, still fundamentally human life has lost respect and dignity and it is a great dilemma in our world today generally, especially in Nigeria. Sometimes for instance patients who are in need of oxygen or other emergency attentions are left to die because they had no money to pay for such palliative treatments. This have been happening and still happens today in our health sectors despite the oath taken by medical workers to protect and uphold the life and dignity of humans, and this inspired this study. On the whole this study will provide answer to the following pertinent questions;

1. Is the respect and dignity for human life in the Nigerian health sector very necessary?

2. Are medical workers in Nigeria convinced of the need to respect the dignity of human life?

3. Does promotion and protection of human rights and of health care fundamentally linked?

4. And how have Nigerian government and health workers fared in the area of respect and dignity of human life in the health institutions?

\section{Review of Literature}

\subsection{Respect and Dignity}

Respect is the feeling of deep admiration for someone or something elicited by their abilities, qualities, or achievements. Dignity is honorableness, a quality of the person being elevated. Human dignity is defined as 'an individual or group's sense of self-respect and selfworth, physical and psychological integrity and empowerment (Gabr, 2016)

Christians all over the world stressed the special dignity of all human beings on the grounds of their spiritual soul, which is the seat of intellect and free will. Certainly, in this tradition, the intrinsic worth of all human individuals is ultimately a consequence of their 
being an "image of God" (Gen. 1, 26), and of their redemption by Jesus Christ. But these theological explanations of human worthiness presuppose that the ultimate internal principle of every human being is spiritual and not merely corporeal (Roberto, 2014). This philosophical assumption is explicit in the thinking of theologians, according to whom the likeness to God is to be found mainly at the level of the soul, not of the body, because God is a purely spiritual being (Thomas Aquinas, Summa theologica, I, 93).

The basis for the theme of Human Dignity, the bedrock of Catholic Social Teaching, is that humans were created in the image and likeness of God. Regardless of any factors or reasons we can think of, individuals have an inherent and immeasurable worth and dignity; each human life is considered sacred. This theme is about our radical equality before God that leads us to think no less of somebody because they are from a different place or culture, because they believe something different to you, or because of their work or employment situation. The principle of Human Dignity means that Catholic Social Teaching takes a strong position on issues around the start and end of life (like the death penalty and abortion) but it also has big consequences for everything in-between. For example it can affect how we think about how our society supports those with disabilities; how we address global inequality and the approach we take to civil rights issues. It is from this idea that all people have inherent dignity that the themes of 'Preferential Option for the Poor' and 'Authentic Human Development' develop within Catholic Social Teaching.

The idea that each life has value isn't something Catholic Social Teaching has a monopoly on; it shares a lot in common with International Human Rights which are also universal, inviolable and inalienable. But Catholic Social Teaching differs slightly because of its basis. It grounds Human Dignity in the firm foundations of the Catholic Church's traditions thought about the sanctity of creation as told in the story of our creation (Genesis) and God's incarnation (Gospels).

For human dignity to be achieved there has to be social equity. Equity is frequently defined as an expression of social justice. It has to do fundamentally with a fair distribution of benefits from health and social development. It goes beyond equality of access to health care. It calls for responses that are in accord with the needs of the individual in relation to the needs for all. From the point of view of health, equity can be defined in various ways: a.) equal resources expended for each individual (supply equity); b.) equal resources expended for each case of a particular condition; c.) equal access to health services; d.) equal quality of health care; e.) equal status of health for all (which is eutopic); f.) Equal healthy life gained per dollar expended; g.) Care according to needs (demand equity). Equity involves both process and outcome. An operational approach would be to assess the impact of specific health decisions on equity and to ensure that decisions taken do enhance equity. One view of equity focuses on the health of the most vulnerable. However, the definition of the vulnerable is not clear. Are they the most sick, the most socially deprived or a group in a certain population such as women, children or the elderly? A distinction is usually made between those who are inherently vulnerable (such as those with a congenital disability) or those whose vulnerability is a result of social construct (such as the poor, women in certain cultures, etc.). An overlap might exist, for example, the deaf, whose inherent vulnerability renders them powerless, are excluded through the social construct from being involved in decisions or resource allocations even if related to their disability, such as cochlear implantation. Ideally, health inequities contingent on factors such as gender, age, residence, education, income, ethnic group, family size, etc. are unacceptable. There are two views on achieving equity. One is the "solidarity approach", which focuses on the society as a whole but may ignore or subjugate the needs of some members or groups. The opposite extreme to 
this approach is "the individual right approach" according to which each individual should have equal access to health care and equal outcome. It is obvious that this can only be achieved in a wealthy, politically stable community. Most third-world countries, which suffer the greatest burdens of disease, cannot fulfill these criteria. Sometimes the right of the individual to attain the highest state of health in a poor country would lead to inequities through exhausting the limited resources available for health in highly expensive health interventions. A balance has to be established where priority is given to support the basic health needs for the community.

\subsection{Human Rights and Human Dignity}

Although the concept of human dignity has been especially developed in the Western world, it is important to note that it is not strange to other cultural traditions. For instance, according to Chinese scholars, it has a correlate in the teachings of Confucianism (Qianfang, 2000, Roberto, 2014). The great Confucian philosopher Xunzi (3rd century BC) said that "Water and fire have essences (Qi), but not life; herbs and trees have life, but no knowledge; birds and beasts have knowledge, but no sense of justice (Yi). Man has an essence, life, knowledge and, in addition, a sense of justice; thus he is the noblest on earth". Xunzi believed that, although people are not innately good, they are all born with the capacity to become good (a "kingly person"), and this is what makes of each individual something special. Another great Confucian philosopher, Mencius (4th century BC), developed a theory of human nature, claiming that the uniqueness of human beings lies not in their bodies, which they share with other animals, but in their moral faculties assembled in their heart-mind (Xin). In this way, Confucianism has given substantive content to the notion of dignity in classic Chinese philosophy by establishing the moral ideals of humanity (Ren) and righteousness (Yi), as exemplified in the moral character of the Confucian gentleman (jünzi), the prototype of the virtuous man (Qianfang, 2000)

Ancient Greek philosophers, in particular Plato and Aristotle, came to the conclusion that the core of every human individual is not just pure matter, but a spiritual principle, which they called soul (anima, psyché). They argued that, since human beings are capable of spiritual activities (understanding, self-understanding, loving, self-determining by judging and choosing, expressing themselves through arts, etc.), they are essentially spiritual beings (Aristotle, On the Soul, III). Precisely thanks to their spiritual component, human beings were regarded as radically unique among living beings and were thought to share in the divine nature (Plato, Laws, V; Timaeus, 90). The modern idea of human dignity was nevertheless not yet clearly present in ancient Greek philosophy, which justified slavery, a rigid hierarchical social order and a sharp distinction between Greeks and other peoples. However, its thoughtful reflections on the spiritual dimension of human beings provided an important basis for the later developments of Stoic and Christian philosophy and theology, which adopted a universal perspective (Roberto, 2014)

\subsection{Protection and Promotion of Human Dignity in the Health Sector}

The promotion and protection of human dignity and rights and of health care are fundamentally linked. The right of the individual to receive correct information facilitated legalizing the compulsory information labels on cigarettes resulting in a positive health and economic impact. There has been a growing tendency in recent years to minimize the burden of public health care on individual human rights. In the past, notification, quarantine, isolation, mandatory, testing, etc. were justified on the grounds of limiting the rights of the few for the good of the many. This is no longer ethically acceptable in many cases. The AIDS 
epidemic is an example where UN policy supports and prevents discrimination against HIV infected people. Human dignity is considered along with human rights to be inherent, inalienable and universal. While important dignity-related health impacts may include such problems as the poor health status of indigenous peoples, a coherent framework of human dignity violations in the field of health is lacking. Taxonomy and an epidemiology of dignity may uncover an enormous field of previously suspected yet thus far unnamed and therefore undocumented damage to physical, mental and social well-being. The relationship between scientific advances, ethics and human dignity will continue to be a focus for discussion and recommendations throughout the next few decades. As far back as 1993, the World Conference on Human Rights in Vienna noted that certain advances, notably in the biomedical and life sciences as well as in information technology, may have potentially adverse consequences for the integrity, dignity and human rights of the individual, and called for international cooperation to ensure that human rights and dignity are fully respected in this area of universal concern.

The health sector has an obligation to consider the ethical implications of the major determinants of health, since causes for inequity or violation of human dignity may originate from outside the health sector. Major determinants include the, economic factors, demographic changes, political system and cultural diversity including the role of women, global ecosystem sustainability, technological advances and as a consequence the changing pattern of disease.

\section{a. Economic Factors}

The relationship between health and poverty is well established. Ill health drags the poor deeper into poverty and poverty increases the risk of ill health. Exceptions are known; examples are Sri Lanka, Costa Rica, Cuba and other countries where leadership support and proper distribution of health care facilities have partially overcome economic constraint. At the global level, however, the situation is more serious. The income disparity between the richest $20 \%$ and the poorest $20 \%$ is increasing. It is estimated that more than 1.6 billion people living in more than 100 countries are worse-off today than they were twenty years ago. According to Toromade (2018) Nigeria continues to cement its status as the poverty capital of the world as more people continue to slip into extreme poverty. An estimated 90.8 million Nigerians are living in extreme poverty as 2018 winds down to a close. It was first revealed in June 2018 that Nigeria had overtaken India as the nation with the highest number of people living in extreme poverty across the world, with an estimated 86.9 million people measured to be living on less than $\$ 1.90$ (N684) a day. According to available data courtesy of the World Poverty Clock, a web tool produced by World Data Lab, that number has increased by nearly four million more Nigerians in just six months (Toromade, 2018).

The enormous imbalance in the distribution of wealth has to be addressed, not only across countries but also between individuals in the same country. The modern concept of health care reform through privatization theoretically imposes health care expenditure on those who can afford it, leaving more resources for the health care of the poor. In reality this is not easily achieved in low-income countries. It deprives a sector of the population of public health services while their income does not allow them to pay the costs of the private or insurance sector. Furthermore, the quality of public health care may deteriorate when health professionals become engaged in part-time private practice to compensate for their low salary scale. Health care cannot be freely commercialized. Can we allow someone, because of poverty, to sell his kidney to some rich person in need? The poor are more vulnerable to certain health risks -- occupational or environmental -- as well as to communicable diseases 
and diseases related to malnutrition. They are also the last to enjoy their rights that might lead to better health. How can people be responsible and accountable for their health when they have little or no control over their living conditions? Their principle preoccupation is likely not to be health but mere survival. Combating poverty and misdistribution of income is not an easy task that will be accomplished in the foreseeable future. However, an ethical and committed approach to ensuring equity in health care would show that we really mean business.

\section{b. Demographic Changes}

The population explosion will continue in many third-world countries during the first few decades of the twenty-first century. The global population quadrupled during the last century from 1.6 billion in 1900 to 6.4 billion in 2000. According to the United Nations department of Economics and Social Affairs (2019), the world's population continues to grow, albeit at a slower pace than at any time since 1950, owing to reduced levels of fertility. From an estimated 7.7 billion people worldwide in 2019, the medium-variant projection indicates that the global population could grow to around 8.5 billion in 2030, 9.7 billion in 2050, and 10.9 billion in 2100. With a projected addition of over one billion people, countries of sub-Saharan Africa could account for more than half of the growth of the world's population between 2019 and 2050, and the region's population is projected to continue growing through the end of the century.

The percentage of dependent population (children, youth, women, elderly and unemployed) constitute more than $70 \%$ of the population in these counties. Most of them suffer from inequities in health care. Trends towards urbanization will continue in the third world with an increase of shantytowns, squatter communities and slum areas. These represent $20 \%$ of the population of certain third-world mega-cities. It is now recognized that the health of urban slum dwellers is even worse than that of those living in remote rural areas, because of overcrowding, and lack of proper sanitation and easily accessible health care facilities. They also suffer from particular health threats -- violence, drugs, sexually transmitted diseases and psychiatric problems. A special approach to ensure that proper health care covers these populations is both an ethical and equity issue. Developing countries where overpopulation control measures are in effect are facing another demographic problem; the rising numbers of elderly people. This, coupled with the increasingly expensive healthcare that is available to the elderly is a major challenge to equity in matters of health.

\section{c. Political System}

Democratization is a prerequisite to ensure the respect of human rights, social justice and equity. The process of democratization is spreading to more and more countries. The progress, however, is relatively slow. Progress in health ethics to achieve equity and respect human dignity should not wait. Attempts to achieve equity in health care are usually welcomed even by the most authoritative regimes. Decision makers play a decisive role in adopting ethical principles in health care that ensure equity, justice and respect for human beings. It is the responsibility of professionals, academicians, as well as ethical, human rights and consumer protection groups to supply decision makers with valid, reliable data on the merits of adopting an ethical code of health care that ensures equity and justice. It is not comprehensible that environmental groups (green parties) could be successful, even in third world countries, in mobilizing public opinion and in getting political support; while health ethics groups still lack a strong political lobby to support their humanitarian goals. Political instability is a great impediment in achieving health for all in certain third world countries. It 
is estimated that more than 10 million lives were lost as a result of armed conflicts during the last decade of the twentieth century, mostly those of civilians, and mainly children. There are more than 50 million refugees worldwide in need of an equitable share in health care. If the human burden of natural disasters is added to these figures, the challenge of delivering proper health care to those people is staggering (Gabr 2016).

\section{d. Cultural Diversity}

The debate about whether ethical principles are universal or diverse and capable of being modified according to prevailing situations has been going on for some time and will probably continue for several decades. It is hoped that globalization will succeed in bridging the gap between different cultures. Cultures, however, including traditions, customs, and religious beliefs, have been deeply rooted in the people for several centuries. The basic principles of ethics are relevant to all but some degree of flexibility in applying them might be required in certain situations. As the late Professor Osontukon from Nigeria noted, "There is a minima of guidelines below which no-one is allowed to fall but above which diversity can be accepted." Along the same principle, notions of dignity and equity must be understood and expressed in terms of the culture concerned. This is necessary for the promotion of sustainable beneficial change as well as to avoid the so-called "moral imperialism". The term "ethical imperialism" was given to the imposition on one society of solutions culturally appropriate to another society on the pretext that they represent ethical absolutes. Certainly no single country has the right to set universal standards with which other countries must comply. However, there is an irreducible set of international ethical standards common to all societies which have to be respected. Let us consider a few examples of the influence of cultural diversity on health ethics. In Japan the human being is a person related to nature and to other human beings. The focus of relationships is more on interdependence than on independence; the family unit is the basis, and too much independence is not much appreciated. The consequences of this interpretation of such ethical principles as confidentiality, personal rights etc. are obvious. In sub-Saharan Africa, human life and health are believed to be under the influence of gods and/or ancestors whose spirits are alive and watchful over their activities. Even when a health condition has a clear-cut physical character, such as an injury, god or spirit may be considered as the remote cause. Traditional therapeutic measures often carried out by medicine men or women in these communities depend on secrecy and privacy. How can the ethical concept of sharing information with the patient be exercised in such a culture? The problem of the treatment of women cannot be underestimated when we consider health ethics, equity, human dignity and cultural diversity. In many cultures even in industrialized countries, women receive less education, less health care and are less involved in decision making at the family, community or national level than men. In traditional conservative cultures a woman cannot commit herself to an informed consent unless she takes permission from her husband. These are examples of cultural issues related to women's health, which exist in spite of the UN convention on elimination of all forms of discrimination against women. They challenge our principles on ethics, equity and human dignity and need more studies on innovative approaches as well as on supporting existing efforts to empower women through advocacy and education (Gabr, 2016).

\section{Research Methods}

This study has been designed in line with survey research using data collected from both primary and secondary sources. The secondary sources comprises of mainly text books, 
journals and periodicals, while primary source is only from questionnaires. The population for this study comprises of all patients and health workers in government owned hospitals in Federal Capital Territory, Abuja, Nigeria, which cannot be easily ascertained. Since every member of the population cannot be reached, this study selected 100 respondents conveniently from the Bwari General Hospital, Kubwa General Hospital and University of Abuja Teaching Hospital using judgmental/purposive sampling techniques; whereby the researcher uses his/her value judgment to select respondents from the population whose opinions the researcher feels relevant to make a valuable decision as supported by Smith, \& Albaum (2010), Orji (2017); Orji \& Enobun (2018); Orji \& Ezinmuo (2019). Questionnaire which consisted of close-ended questions, were used. The adapted questionnaire was designed in line with four likert scale of Strongly agree (SA) Agree (A), Strongly Disagree (SD), Disagree (D). Data were anaysed using simple tabulations and percentages. The percentage is for the comparisms of respondents that responded for or against a particular question in relation to the overall respondents expressed as a percentage in order to see the pattern of response.

\section{Discussion}

The result of analysis conducted revealed that, out of 100 questionnaires administered, 84 were returned valid, making 84 percent, enough to form good opinion. The analysis also revealed that of this, majority of 62 respondents $(74 \%)$ by way of strongly agreed, and agreed that respect and dignity for human life in the Nigerian health sector is very necessary. Also 72 respondents $(86 \%)$ agreed that medical workers in Nigeria are convinced of the need to respect the dignity of human life, and promotion and protection of human rights and of health care are fundamentally linked. Equally, 78 respondents $(93 \%)$ agreed that Nigerian health workers have not fared well in the area of respect for human dignity, while 76 respondents (90\%) agreed that Nigerian government policies and cultures have impeded the protection of rights and dignity of persons in the health sector.

\section{Conclusion}

This study draws its conclusion on the fact that workers in the health sector and to anyone who respect and defend the dignity of human life from its initial existence to the end, should continue to work tirelessly inculcating this culture to other people in Nigeria. The recourse to dignity in this specific area reflects a real concern about the need to promote respect for the intrinsic worth of human beings and the urgency to preserve the identity and integrity of the human species against potentially harmful and unethical practices in Nigerian health sector.

Based on the findings, the study makes the following recommendations:

1. There is the need for reformation of the health care sector planning it in such a way that respect and dignity for human life will reflect in the centrality of the programme of reformation and activities.

2. Education of the Nigerian health workers on the need for respect and dignity of human life in the health care institutions, and Change of mentality through media

3. Policy makers and stakeholders in the health sector should be accurately selected and oriented primarily to be conscious of the respect and dignity of human life so that it will reflect in their policy making. 


\section{References}

Gabr, M (2016) Health Ethics, Equity and Human Dignity' Cairo University, Egypt Press

Orji, M.G (2017). Impact of Personality Factors on Consumer Buying Behavior of Textile Materials in South Eastern Nigeria (PhD Thesis) Department of Business Administration, Ahmadu Bello University, Zaria, Nigeria.

Orji, M.G, Enobun, P.N (2018). Effect of Work Environment on Teacher Commitment to Duty in Selected Secondary Schools of South Eastern Nigeria, 'Management", (MANA) International Technology and Science Publishers (ITS) United Kingdom. Vol. 1. PP 61- 78. www.itspoa.com/journal/mana

Orji, M.G \& Ezinmou, M.E (2019) Effect of Financial Incentives on Employee Work Habit and Performance in Nigerian Public Enterprises' International Journal of Research in Finance and Management; Vol. 2(2): 13-22. http://www.allfinancejournal.com/article/view/30/1-2-27

Qianfang, Zhang, "The Idea of Human Dignity in Classical Chinese Philosophy: A Reconstruction of Confucianism", Journal of Chinese Philosophy, September 2000, 27(3): 299-330.

Roberto, A (2014) Handbook of Global Bioethics, Dordrecht: Springer, pp. 45-57

Smith, S. M \& Albaum G. S (2010) An Introduction to Marketing Research, Sage Publishers, NY, P 129.

Toromade, S (2018) 'Nigeria ends 2018 with 90.8 million people living in extreme poverty' https;//www.pulse.ng/news/ accessed 16/11/2019.

UNDES (2019) 'World population Projects 2019' https;//population.un.org/ accessed16/11/2019

William E. M (2008) Catholic bioethics and the gift of human life. Second edition Our Sunday Visitor. USA

The New Jerusalem Bible, (1985). Doubleday Edition, New York.

Encyclical Letter, Evangelium vitae, 25 march 1995,

MIGLIETTA G.M., Respect for Human Life in its Origin and the Dignity of Procreation

“CDFInstruction Donum Vitae, (1998) An Appraisal”, Arti Grafiche TSG, Asti - Italy. 